Association for Information Systems

AIS Electronic Library (AISeL)

2016

\title{
Understanding the Internet Pitchfork Mob: Internal Revolutionary Activity in Self-Regulated Online Communities
}

\author{
Catherine Olivia McRae \\ Assurity Consulting, cat.mcrae@assurity.co.nz \\ Jean-Gregoire Bernard \\ Victoria University of Wellington, jean-gregoire.bernard@vuw.ac.nz \\ Jocelyn Cranefield \\ Victoria University of Wellington, jocelyn.cranefield@vuw.ac.nz
}

Follow this and additional works at: https://aisel.aisnet.org/acis2016

\section{Recommended Citation}

McRae, Catherine Olivia; Bernard, Jean-Gregoire; and Cranefield, Jocelyn, "Understanding the Internet Pitchfork Mob: Internal Revolutionary Activity in Self-Regulated Online Communities" (2016). ACIS 2016 Proceedings. 64.

https://aisel.aisnet.org/acis2016/64

This material is brought to you by the Australasian (ACIS) at AIS Electronic Library (AISeL). It has been accepted for inclusion in ACIS 2016 Proceedings by an authorized administrator of AIS Electronic Library (AISeL). For more information, please contact elibrary@aisnet.org. 


\section{Understanding the Internet Pitchfork Mob: Internal Revolutionary Activity in Self-Regulated Online Communities}

Catherine Olivia McRae

Victoria Business School

Victoria University of Wellington

Wellington, New Zealand

Email: cat.o.mcrae@gmail.com

\section{Jean-Grégoire Bernard}

Victoria Business School

Victoria University of Wellington

Wellington, New Zealand

Email: jean-gregoire.bernard@vuw.ac.nz

\section{Jocelyn Cranefield}

Victoria Business School

Victoria University of Wellington

Wellington, New Zealand

Email: jocelyn.cranefield@vuw.ac.nz

\section{Abstract}

Research into organised online protest typically focuses on how digital activism empowers social movements. But what if an online community is rebelling against its platform owners? This study seeks to identify the trajectory of internally focused revolutionary activity in self-regulated online communities. Based on an analysis of three cases (Reddit, 2015; Mozilla, 2014, and Skyrim, 2015) it identifies six stages of revolution: incident, reaction, mobilization, action, negotiation, and a return to 'normality' with a new power equilibrium. For each stage, key events, relations between the community and platform managers, and the ways in which power is enacted through online means, are identified. This preliminary model for online community revolution offers potential for further work that has diagnostic, predictive and ameliorative value. Relations with online communities are of significant value in an era in which many platform-related business models are reliant on voluntary contributions of selfregulating online communities.

Keywords: online activism, online communities, revolution, digital protest, process model 
"Do it, you have nothing to lose. And there's nothing like a good protest."

/u/joper9o (Reddit, 2015)

\section{Introduction}

What happens when an online community mutinies? In July 2015 Reddit, a well-known entertainment site known as 'the front page of the internet' was plunged into chaos as the community openly challenged the leadership of the site, effectively creating a dividing line between the administrators of the website and the people who used it. At times referred to as the 'Reddit Revolt' (Hartmann, 2015), this uprising saw the majority of boards that users frequented locked by its moderators (Isaac, 2015). This was intended as protest against the lack of support and respect moderators felt they were receiving from the administration team (Lynch \& Swearington, 2015). By sending the 1oth largest website in America into complete darkness until their terms were met, the moderators of Reddit reminded Internet users everywhere they can mobilize to affect change. The ripples from this were so strongly felt that the CEO of Reddit, an organisation at the time worth almost 250 million US dollars according to one report (Elder, 2015) stepped down from her position shortly after the community's protests (Isaac \& Streitfield, 2015).

The example of the Reddit Revolt is only one of the more recent cases where an online community has opposed the pre-existing power relationship on its platform. Other communities have risen up against their existing leadership, for a variety of reasons - a phenomenon the internet affectionately refers to as the 'internet pitchfork mob'. Yet while individual deviance online is a well-explored phenomena, little is known about organized mass disruption that is constrained to the digital sphere. Research has been focused around digital protest which has an offline cause, such as the use of social media in the Arab Spring uprising, but there has been little coverage of mass disruption localised within an online community.

Online communities today have become a new locus of socialization and media consumption, and can exist autonomously from their platform owners, through generating their own content and upholding their own governance. Online communities have become increasingly self-regulated, where the community creates and upholds its own rules and elects leaders from within to manage daily control. A shared commonality of intent (Plant, 2004) binds these communities together, and their rules are shaped to their own shared ideals. The platform owner takes a secondary role for these communities, but usually gains some sort of value from them, be it profit through page views or through their contribution to an activity. This presents a new challenge for these owners when disruption occurs; how to exert control over a self-managed crowd?

The purpose of this paper is to develop a process model of mass rebellion in self-regulated online communities to protest the leadership of their online community. The tactics exhibited by these communities bears similarities to traditional revolutionary activities, both in their concept and their modus operandi. Our focus is primarily on organized movements of a significant part of a site working towards a common goal that is local to the community, rather than on the behaviour of deviant individuals (e.g. trolls), or political movements (e.g. women's rights, tea-party). The study was guided by the research question, What is the trajectory of revolutionary activity in self-regulated online communities? In order to respond to this question, a qualitative inductive multi-case study was conducted. Three cases that focus on examples of online community revolution are used for contrast and to create a deeper understanding of the social processes studied. A conceptual framework is proposed: a phase model detailing the trajectory of revolutionary activity in self-regulated online communities.

\section{Literature Review}

How the Internet changes human interaction within online communities is an area that has seen much research. Suler (2004) proposed that inhibition was reduced by the lack of physical cues online, leading to a reduced sense of consequence. This so-called disinhibition effect is one of the key reasons for trolling and other deviance online (Bergstrom, 2011). Bad behaviour and non-coordinated deviance from the rules set by platform owners, is commonplace, and at times difficult to manage. Deviant behaviour has seen much investigation, with theories ranging from deviance being an important part of online citizenship (Nielsen, 2008) to deviance creating a new toxic culture where cyber-bullying is commonplace (Massanari, 2015). 
A commonality of this work is the focus on the deviant as an individual: bad behaviour is typically written as something that is committed by an individual, or a small group within a community. But what if the group breaking rules or norms is, in fact, the majority? The abilities available to an individual - writing aggressive comments, threatening or stalking other users - differ greatly to what a collective is able to achieve. Whereas an individual acting in deviance is defying the traditional power structure by refusing to comply, a collective acting in a way that is unexpected and against rules or norms has the potential to shift power in a massive way that is currently unexplored. This creates new challenges from a managerial perspective; there are well-researched ways to handle deviant individuals, but little understanding of how a deviant collective acts, making it difficult to control and manage. Online communities have become increasingly integrated into modern life, and protest has begun to emerge in these digital spaces, yet dissidence that occurs at the level of the online community and the consequent managerial impact is a phenomenon which has been little researched.

Online communities are groups of users who communicate, bond and share resources, often united over a shared interest or common goal (Huffaker, 2010) and guided by a set of shared norms, values and rules (de Souza \& Preece, 2004; Preece, 2000). As there is great diversity in which constitutes an online community (Kraut \& Resnik, 2012), researchers have proposed different typologies in the interests of establishing conceptual boundaries. For example, Plant (2004) proposes a typology based on degrees of openness, community regulation, and for-profit activity. Understanding how communities (self) regulate seems likely to assist in understanding online revolution. However, there is a curious lack of work around protests originating or existing purely within the digital sphere. There is, however, research that places attention on how the Internet, and notably Web 2.o tools, have transformed the wider means of social and political activism. This area of study, at the intersection of social movements and ICTs, is known as internet activism (Earl, Hunt \& Garrett, 2014). The last 20 years has seen much collective action worldwide, and the Internet has helped enable some political protests significantly - for example, the use of Twitter in the Arab Spring triggered a flurry of research into the implications of social media for pre-existing political protest (Hermida, Lewis \& Zamith, 2014).

Recent work has looked more closely into the interaction of technology and social activisim: for example, in relationship to the anti SOPA (Stop Online Piracy Act) movement, Yetgin, Young \& Miranda (2012) identified how cybermediaries (Internet companies) engaged in cultural productions of protest frames and technology-based toolkits to promote the SOPA movement, while Miranda, Young and Yetgin (2016) show how interpretive media packages had emancipatory effects on structural constraints (authorship, citation and influence) but a hegemonic effect on content frames. In a longitudinal study of the Swedish affiliate of Amnesty International, Selander \& Jarvenpaa (2016) identified the use of specialised digital action repertoires within networks to support claims-making performances targeted at authorities.

Research on Internet activism is seen as an active frontier in which it is necessary for authors to tailor their theoretical findings to the type of activity and technology under study (Earl et al., 2014). Earl et al. (2014) identify four broad kinds of internet activism; brochure-ware, online facilitation of offline activism, online participation, and online organising. Online organising, fully online campaigns and movements, is the least studied form of Internet activism (p.432). Our study, focused on understanding the process of online revolution in self-regulating online communities, aims to help address this gap.

\section{Methods}

\subsection{Research Design}

The purpose of this research is to understand how revolutionary action unfolds in online communities, and develop a process model to explain this phenomenon. Internally-focused revolutionary activity in online communities is a phenomenon that has seen little investigation, and is poorly understood. Inductive case research is particularly appropriate for developing theory in areas that have been little charted (Corbin \& Strauss, 2008). We employed an inductive theory building multiple-case study. Our analytical strategy consists of a process tracing approach which aims to unearth recurring empirical regularities, by temporally bracketing sequences of events in online revolutionary action (George \& Bennett, 2005; Langley, 1999; Miles, Huberman \& Saldaña, 2013). This analytical strategy has been commonly used by studies aiming to highlight the staggered process of collective action during revolutions (Goldstone, 2001).

\subsection{Case Selection}

To select the cases, a theoretical sampling approach was used. Cases were selected if they appeared to exhibit strong signs of the key phenomenon of interest: a virtual community appearing to oppose their 
online leadership on a large scale. Following a broad scan of online media, we selected three cases, aiming for a balance of strong reported disruption, sufficient scale and detail of information to support close examination, and a diversity of contexts and ways in which events unfolded. The cases selected were Reddit (events in 2015), Mozilla (events in 2014), and Skyrim (events in 2015).

\subsection{Data Collection and Analysis}

Two techniques for locating data were employed; firstly keyword searching was employed, then an exploratory manual scan. Keyword searches used the basic facts of each case - 'Reddit lock out', 'Reddit black out' and 'subreddit shutdown' are examples of three searches used for the Reddit 2015 case. Searching was undertaken first on a general search engine, then on relevant social networks to each case. Using time-specific information gained from the media to guide collection, online archival data was gathered at the source of each event (Kozinets, 2015): publically accessibly forum logs, social media artefacts, blog posts and online petitions, depending on the platforms where revolutionary activity took place. When sampling source data, consideration was given first and foremost to the proximity of the data source to key events of the cases. If a source was a direct record of an event that exhibited revolutionary activity it was included. In total 47 sources were gathered, including media documents. Media works were used to provide background about the cases, leaving 35 sources used for primary analysis. This dataset equated to 186 printed pages of qualitative data.

The first step of the analysis consisted of analytic memo writing (Saldaña, 2015). For each case we composed a memo of about 7 pages outlining the narrative arc of the case, the main actors and their stakeholders, the digital platforms employed, and the context in which events took place. These memos were used as the basis for the subsequent development of codes. Coding was completed in three steps. The first step involved inductive process coding for each case in an independent manner, and saw 170 codes assigned. Process coding was selected as it is particularly appropriate for studies that search for "ongoing action/interaction/emotion taken in response to situations, or problems, often with the purpose of reaching a goal or handling a problem" (Corbin \& Strauss, 2008, p.96-97). Because of the multiple actors involved coding was done in a way that reflected the complex, emerging nature of the revolutionary process taking place in each case, by taking multiple perspectives (e.g. users, moderators).

The second step employed axial coding to compare each case and relate the inductive codes to each other. Axial coding aims to determine the dominant and lesser codes in the research, and to eliminate redundant codes, so that the most theoretically significant codes remain (Corbin \& Strauss, 2008). In this cycle four main conceptual categories were identified, with forty sub-categories associated with these.

In order to surface the deep structure of the revolutionary process followed by all three cases, composite sequence analysis (Miles et al., 2013) was then used. Composite sequence analysis is particularly appropriate for extracting a shared story between cases, without destroying meaningful sequences (Miles \& al., 2013). We mapped each case in timeline form, noting the processes occurring throughout the trajectory of revolutionary action, then grouping codes across cases chronologically. If a code was conceptually analogous and the underlying ongoing action/interaction/emotion had resemblance across cases it was recognized as an event or phase significant to the development of revolutionary action in online communities. This overlaid the individual stories of each case to create a shared revolutionary trajectory.

\section{Findings: Trajectory of Revolutionary Activity}

In each of the three cases the online communities were found to have gone through a series of five distinct revolutionary stages. These common stages are shown in Figure 1. The narrative below outlines the detail of each stage, detailing the ways in which the community successfully self-managed and leveraged power and resources in order to enact change. 


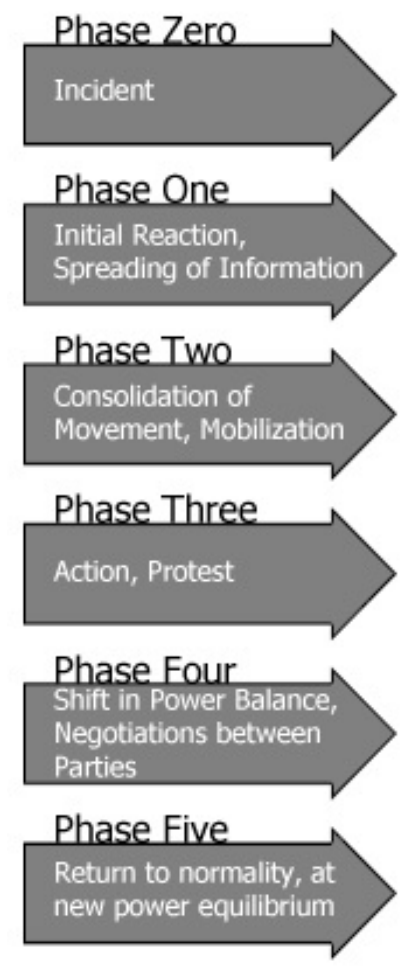

An incident occurs between an organization and its community that strains relations, and aggravates the online community.

News of the incident spread via 'word of mouth' through community and via the media. Users discuss news and collectively determine their stance. Emotional responses common at this point.

Community begins to reach out and encourage involvement from others, using social networks to communicate. Protest planning begins, intent is communicated to offending party.

Action begins. Multiple forms of protest are employed across multiple domains, such as boycotting, petitioning, soapboxing, lock-outs, and letter (email) writing.

Offending party reaches out to aggrieved community in attempt to placate them, offer explanations. More open discussion between parties begins.

Some closure is reached; either the community achieves their goal or compromise is made. Protest halts, and a slow return to normal affairs follows, but with lingering tension between parties. A new power equilibrium emerges, and an adjustment period may follow.

Figure 1: Trajectory Model of Revolutionary Action in Online Communities

\subsection{Phase Zero: Incident}

In each case a key event (Phase Zero: Incident) occurred to disrupt the community and damage their relations with the governing party. The existing relationship between community and governing party differed in each case, but a specific trigger was needed to spark revolutionary action. This occurred when an action by the owner of the community threatened the online community's sense of control.

In each case the objection from the community was born not just from the specifics of the incident, but also from the lack of consultation before the decision was made. In each case the collective felt strongly that they ought to have been informed and that their input should have been key. The self-governing nature of these communities decreased their perception of their owning party's authority, and as they managed their own affairs on a daily basis they felt that they were more qualified to make decisions that would befit their needs.

\subsubsection{Case One: Reddit 2015}

Reddit is a popular for-profit media consumption site, with over 234 million users who create their own content (or repost other's), comment on it, or share it for 'karma.' The site is privately owned, with governance controlled by Reddit Administration. Administrators typically do not interfere with the site on a daily basis, leaving day-to-day management to the community, in particular the user-elected moderators.

On 2nd July, 2015, one of Reddit's most well-known and beloved administrators, Victoria Taylor, was removed from her position without warning. Taylor's role was Director of Talent for the site, and involved closely working with many of the site's volunteer moderators, who relied on her to be able to complete their duties (Lynch \& Swearingen, 2015). The lack of warning about Taylor's dismissal aggrieved the moderators who had worked with her, who felt they ought to have been informed and a support system put in place to ensure they were able to continue their work without her (Lynch \& Swearingen, 2015). Reddit's moderators are volunteers who uphold the self-made rules for the Subreddits (forums dedicated to a topic) that they run. This change disrupted their ability to govern, threatening their control over the general community.

The moderators had felt the work they did had long gone unappreciated by Admin, and this feeling bubbled to the surface in light of the incident (Matias, 2015). Because the community had become 
increasingly frustrated with their Admin team for several months prior, unrest was rife already. The incident was all that was needed to trigger an explosion that would set the site ablaze.

\subsubsection{Case Two: Mozilla 2014}

Mozilla Corporation, best known for their browser Firefox, hosts a large online community of volunteers who collaborate to create open source software for Mozilla. The community divides into small groups to work on different projects, electing temporary leaders for each project (Bahrami, 2013). Known to each other as 'Mozillians', this community is known to be tight-knit, and strongly motivated (Bahrami, 2013).

On the 24th March, 2014, Mozilla elected a new chief executive, Brendan Eich. Longstanding senior Mozillian, and inventor of Javascript, Eich was well-known within the community. Eich had previously received some negative publicity that had damaged his standing with the community (Barr, 2014). In 2012 it was revealed that he had donated money to the contentious Californian state bill, Proposition 8, which sought to make gay marriage illegal within the state. Eich's $\$ 1000$ donation had caused distress within the Mozilla community, with many of its LGBT members feeling threatened by his support of the bill. The promotion of Eich to CEO brought memories of this past conflict to the forefront of the community's mind.

\subsubsection{Case Three: Skyrim 2015}

A cornerstone of the PC gaming community, Valve Corporation is one of the most prominent digital distribution companies online. Valve is best known for Steam, their online game distribution platform and community forum. One of the most popular titles available on Steam is publisher Bethesda Softworks' The Elder Scrolls V: Skyrim', a game which was popular with 'modders'- gamers who created their own modifications to the game and shared them with others. Over 26,00o mods were available for Skyrim, many of which were considered critical to enjoy the game. The Skyrim community hosts the least formal self-governance structure, based around shared values and implicit codes of conduct rather than a hierarchical system.

The Skyrim community had long held a positive relationship with Valve, and saw their needs and views as aligned. This had instilled a strong feeling of trust between the two parties (McWhertor, 2015). However, with this trust came expectations, and when these expectations were contradicted by Valve's actions then a feeling of betrayal incited the crowd. On the 24th April 2015, Valve and Besthesda Softworks announced that the Mod Workshop on Steam for Skyrim would be monetised, effective immediately. The system was opt-in, allowing creators to set the price of their mod, or leave the mod free to download (Alden, 2014). The community resented the change being forced upon them, and felt threatened by the perceived betrayal, seeing the Mod Workshop as a commercial 'invasion' of their space.

\subsection{Phase One: Initial Reaction}

Phase One: Initial Reaction is characterized by the online community discussing the incident, and forming a shared frame of the event. Multiple platforms were typically employed in this stage, with communities tending to favour a platform that would allow for quick, rather than detailed transfer of information. Phase One was dominated by the need to share news, rather than to discuss deviance.

Control on Reddit resides with moderators, whom are widely acknowledged as the key reason the site has any semblance of order at all. Typically moderators are elected from within the community after their contributions as a member have been recognised. This lends them sway over the collective, who trust and feel kinship with a self-elected leader (Huffaker, 2010). When news of Taylor's dismissal and the impact it was having on the moderators broke, users banded behind them in support. Because the administration team (with the exception of Taylor) barely interacted with the community, users felt no connection the administration, and were quick to frame the administration as the aggravating party.

Mozilla operates as a self-regulated community, but has a close working relationship with its administration, with staff and volunteers collaborating often. This has meant that the community has enjoyed significant input into decisions made in the past, and alignment between the two has typically been strong. A shared ideology of openness and acceptance is one of the core community values, and something that draws volunteers. The election of Eich, and his apparent opposition to gay marriage compromised both this ideology, and the alignment between parties. The community was initially divided, with many arguing that if Mozilla wanted to be an accepting community, they should also allow for opposing views such as Eich's. The majority of this discourse occurred through Twitter, though as this phase extended there was a shift to blog posts so that more detail could be expressed. The consensus eventually reached was that Eich's views were irreconcilable with the community's ideology. 
Valve and Besthesda Softworks' announcement of the monetisation plan was met with ire from the gaming community as a whole, and naturally from the Skyrim player base in particular. The news of the new system was spread quickly by the gaming and technology media (which has a close relationship with the community) and soon gaming forums were debating the issue intensely. It was agreed that the community opposed monetization of user-made mods if the creators were not the main parties who were going to profit. The issue of control was evident; users feared not only for control over their own content, but also for the future of their community and their ability to shape it to their own values rather than Valve's.

\subsection{Phase Two: Mobilization}

Phase Two: Mobilization, is where the decision to 'pick up the pitchfork' takes place. Once the community's discourse on the matter has completed then the 'mob' begins to form and communicate its intent. In this phase a movement coalesced and strategies for mass deviance were developed. The degree of self-governance each community exhibited had a direct impact on this phase; the more independent the community and the stronger their internal hierarchy was, the more effectively they were able to mobilize.

A sense of solidarity was strong within Reddit as they began to mobilize against their administration. Many subreddits that were unaffected by the incident felt they ought to support the subreddits that had, and regular users encouraged moderators to 'stand up for themselves' and pledged to do whatever they could to help. Users began to create petitions to return Taylor to her role, and requesting that the CEO step down, while moderators began plans to co-ordinate a "black-out". One of the key moderator roles on Reddit is the ability to set the view access of the subreddit they run. Moderators deliberated about the efficacy and impacts of limiting access to the site's content in order to communicate their disapproval of the administration.

Mozilla, as a volunteer organization, had vastly different resources to draw upon, and mobilized accordingly. They chose to collectively withdraw their shared man-power and their existing work from the organization and shift elsewhere. Only a day after Eich's appointment, the first objection was voiced by Hampton Catlin and his husband, Michael Lintorn Catlin; Mozillians who also developed apps and add-ons for Mozilla Firefox. The Catlins announced that they were pulling their apps from Firefox, effective immediately, and stated that they were unable to support an organization with a CEO that had actively opposed their right to be married (Catlin, 2014). This triggered an emotional response from much of the community, who began to follow their example and express their intent to withdraw their work to Mozilla.

The Skyrim community considered leveraging a different kind of power - not that of the worker, but that of the consumer. They began to plan consumer boycotts where they would no longer buy Bethesda's games or any games on the Steam service, and encouraged each other to compose emails to Valve to inform them that they would cease their purchase of Valve's products. A 'black-out' day was planned a week from the announcement, where they would completely cease use of the Steam platform. This community was the most active in their recruitment, with users actively encouraging each other and reaching across multiple gaming sites in order to further their cause.

\subsection{Phase Three: Action}

Phase 3: Action formed the core of the revolutionary movement for all three cases, and media attention was centred here. Strategies designed in the previous mobilization phase were executed in this phase, with the intent to be as disruptive as possible. Multiple methods and strategies were employed by communities in this phase; it was rare to see one method applied alone. Typically easier to execute forms of protest such as petitions were applied alongside more manifest methods such as boycotting. The longer the action phase spanned, the more forms of deviance the community employed as they looked to trigger a response.

In this action phase many of Reddit's moderators claimed control of their subreddits, blacking them out and refusing access to all regular users. Soon Reddit was effectively crippled, with much of the site's content completely inaccessible to its users. Some communities remained open but posted a message of solidarity, and others participated briefly (Hutchinson, 2015). Regular users responded in support of the moderators by creating their own protests, such as a financial boycott where users were encouraged not to buy Reddit Gold (one of Reddit's main income streams.)

Mozilla fans also utilized the consumer boycott, encouraging each other to uninstall Firefox (Mozilla's main product) and switch to other browsers. There was fierce media interest at this point, particularly because of the connection to existing broader social movement - the LGBT movement. Volunteers and 
employees used Twitter and the blogosphere as a medium for protest to call for Eich's resignation, and a corresponding petition reached over 70,000 signatures (Barr, 2014). Volunteers began to remove themselves from the community, and some donors threatened to withdraw monetary support from the Mozilla Foundation. At the peak of the controversy, three of Mozilla's six Board members stepped down simultaneously, though they did not explicitly cite Eich's appointment as the cause (Mozilla Press Center, 2014).

Skyrim players rapidly employed their various forms of protest in unison. A Change.org petition by the wider gaming community reached 130,000 signatures in just three days, while others realized that their emails of protest to Valve could serve a more destructive purpose by deliberately clogging their Support line, and indirectly causing fiscal damage. As another form of protest, Skyrim modders began creating free mods that mocked the situation, notably creating a rich beggar that ran throughout the game and demanded money for no reason to represent Bethesda (McWhertor, 2015). By creating more free mods, and refusing to participate, the modders within the Skyrim community effectively staged a boycott.

\subsection{Phase 4: Negotiation}

While the first three phases observed segued naturally into each other, Phase Four: Negotiation differed in its abrupt beginning. All other phases are community led, but the negotiation phase is triggered when the site administration approaches the deviant community to negotiate a ceasefire to their protests. The self-governing nature of the communities meant that administration had no means to exercise control and curb the crowd's disruptive behaviour, tipping the balance of power heavily in favour of the users. The dependency that the owning party had on a community that did not rely on its leadership was heavily evident to both parties in each case.

After several hours of the 'Black-Out' occurring, Reddit's administration reached out to their moderators to negotiate. A great amount of media interest had been generated at this point, and the matter had shifted from simply a community problem to a major threat to Reddit as a business venture. Negative press was mounting, and the cease of traffic to major parts of the site was a chokehold on Reddit's revenue. The administration team began frantic negotiations with the moderators of the site to end the black-out, which was initially met with some derision from the community, who refused to yield until they were satisfied there would be a long-term plan to improve the support moderators would receive from administration. After 3 days a formal apology and plan to move forward was posted, and CEO Ellen Pao resigned from her position (Matias, 2015).

Negotiation between Mozilla and the community opened and closed quickly with the resignation of Eich from Mozilla. Two weeks after his appointment, Eich stepped down from his position, announcing "Our mission is bigger than any one of us, and under the present circumstances, I cannot be an effective leader" (Barr, 2014). Mozilla formally apologised soon after, stating "Mozilla prides itself on being held to a different standard and, this past week, we didn't live up to it. We know why people are hurt and angry, and they are right: it's because we haven't stayed true to ourselves" (Baker, 2014).

The Skyrim community spent some time in the negotiation phase as they initially rejected contact by their owning party. Valve and Bethesda both tried to diffuse their situation at first, with Valve going to the extent of having their CEO interact with the incensed community, but because he offered no real change this had no real impact (Orland, 2015). Four days after the announcement, Valve completely removed the new changes, and issued an official apology. They also refunded anyone who had purchased a mod. Bethesda released their own apology, although both companies stressed that their only error had been to interfere with a well-established community. Protest then immediately ceased.

\subsection{Phase Five: Normality at a New Equilibrium}

The final phase, Normality at New Equilibrium saw mass deviance draw to a close and a slow return to daily affairs. Typically, change had occurred in the power dynamic by the time a new equilibrium was reached, with the administration promising to involve the community in decision-making in future. Phase Five lasted longer for communities that had deep-seated tension before the original triggering incident occurred, as a greater level of trust needed to be rebuilt between parties.

Because the relationship between Reddit's moderators and the administration team had been strained for years, Reddit was left in a state of reconciliation even 6 months after their conflict. It was evident that the moderators were distrustful that any actual change would occur - many of them expressed that they felt that they had been led by 'empty words' into re-opening their subreddits, and monitored the administration team sternly to ensure they met their promises. 
For Mozilla, this last phase resulted in a shaky tension within the community. Many felt that Eich shouldn't have been forced to leave his position because he expressed a different opinion. By and large though, the community appeared satisfied that the conflict was resolved with Eich's resignation and the community's attention had shifted to other matters, signalling an exit from Phase Five.

The Skyrim community had enjoyed an excellent relationship with Steam prior to Phase Zero, resulting in a brief final phase, and a relatively speedy exit from the revolutionary cycle. For the gaming community, they had created a boundary and communicated it clearly to their governing party - as long as this boundary continues to be respected, they will continue to remain in good relations. The previous good standing between parties meant that trust was easy to restore between them.

\section{Discussion \& Conclusion}

How do you control a self-managed crowd? The self-regulation approach for online communities has grown in popularity in recent years, particularly for media consumption sites such as Buzzfeed, Reddit and Tumblr. These sites rely on their users for their patronage and their production of content, yet the users rely little on the platform owners, and feel no loyalty towards them. This can be a mutually beneficial arrangement, provided that relations remain positive between parties. It is in the face of a relationship meltdown that the independence of the community equals a loss of control for the owner and an inability to enforce power over the crowd when large scale deviance is occurring. Research in online protest has focused around digital activism (Earl et al., 2014; Hermida et al., 2014), while research around mass deviance is limited to state-directed revolutionary activity (Goldstone, 2001) or organizational power mechanisms (Pfeffer \& Salancik, 1978; Rao \& Dutta, 2012) Yet, the for-profit selfregulated online community is an increasingly common business model nowadays. Internal revolutionary action presents a significant threat to this business model, and there is a need for research that attempts to understand these new dynamics.

A key theoretical implications of this study is that future research will have to problematize the notion of online community citizenship. A common finding is that citizenship behaviours are critical for the vibrancy of an online community (cf. Bateman, Gray \& Butler, 2011). Yet, some forms of citizenship behavior may benefit the community itself while other forms of citizenship behavior may run contrary to the interest of the platform owners. Deep involvement of users may generate valuable contributions for both the community and the platform owner, but may be also accompanied by heightened expectations of voice in major platform decisions. The higher the commitment users have toward a community, the more adverse their reaction can be when their expectations are violated, thus making relationships between parties difficult to repair (Brockner, Tyler, \& Cooper-Schneider, 1992). While our study showed that online revolutionary activity is causally complex, future work could develop models of dynamics based on theories of trust, social justice (Greenberg \& Colquitt, 2013) and power (Pfeffer \& Salancik, 1978). Such models could be used to simulate the process and outcomes of revolution in online communities (Davis, Eisenhardt, \& Bingham, 2007), by testing configurations of mechanisms underlying the emergence and outcomes of revolution.

This study is conditioned by at least two key limitations. First, this work relies solely on archival analysis. Case studies are strengthened by the triangulation of data types, so employing a singular type of data can narrow understanding of a phenomenon; for this study, an etic perspective (Strauss \& Corbin, 2008; Miles \& al., 2013). Future work should consider adding interviews from actors involved, to tap into the emics of the revolutionary process. Another potential limitation relates to bias, since the researcher is critical as an instrument (Denzin \& Lincoln, 1994). In order to minimize the potential of this bias, we used peer review procedures with online community members to check on our memos and interpretation of the events.

Although crowd-based business models have great potential for value creation and innovation, the crowd can also be of great political and financial threat if left unchecked. The self-regulated online community protests in ways unlike conventional social movements: it can become a mob with no formal movement organization, no central spoke-person with whom to liaise, and no clear boundaries. As our cases illustrate, this mob acts quickly and swiftly. Yet, despite the blistering speed at which the rebellions unfolded, there are nonetheless discernible phases of the process which this study helped to surface. Platform managers of self-regulated communities have to learn how to listen to the crowd's discontent and consider the risks of rebellion. And even after a rebellion has begun, our model can help platform managers understand what is happening: the likely trajectory can be forecast, each phase considered, and appropriate steps taken to mitigate escalation and speed up resolution. Based on the actual outcomes of our cases - ousting of CEOs, rebuttal of monetization strategy -, we have shown that these digital rebellions can have real impact. 


\section{References}

Alden, K. 2014. Introducing New Ways to Support Workshop Creators. Retrieved from http://steamcommunity.com/games/SteamWorkshop/announcements/detail/208632365237576574

Barr, A. 2014. "Mozilla CEO Brendan Eich steps down,” Wall Street Journal. Retrieved from http://www.wsj.com/articles/SB100014240527023035.32704579479741125367618

Baker, M. 2014. Brendan Eich Steps Down as Mozilla CEO. Retrieved from https://blog.mozilla.org/blog/2014/04/03/brendan-eich-steps-down-as-mozilla-ceo/

Bahrami, H. 2013. "People operations at Mozilla Corporation: Scaling a peer-to-peer global community," California Management Review (56:1), pp 67-88.

Bateman, P.J., Gray, P.H. \& Butler, B.S. 2011. "The impact of community commitment on participation in online communities," Information Systems Research (22:4), pp 841-854.

Benford, R. D., \& Snow, D. A. 2000. "Framing processes and social movements: An overview and assessment," Annual Review of Sociology (26), pp 611-639.

Bergstrom, K. 2011. "Don't feed the troll - Shutting down debate about community expectations on Reddit.com," First Monday (16:8).

Brockner, J., Tyler, T.R. \& Cooper-Schneider, R., 1992. "The influence of prior commitment to an institution on reactions to perceived unfairness: The higher they are, the harder they fall," Administrative Science Quarterly (37:2) pp 241-261.

Catlin, M. 2014. Goodbye Firefox Marketplace. Retrieved from http://www.teamrarebit.com/blog/2014/03/24/goodbye_firefox_marketplace/

Corbin, J., Strauss, A. 2008. Basics of Qualitative Research: Techniques and Procedures for Developing Grounded Theory ( $3^{\text {rd }}$ ed.). Thousand Oaks, CA: Sage.

Davis, J.P., Eisenhardt, K.M., \& Bingham, C.B. 2007. "Developing theory through simulation methods," Academy of Management Review (32:2), pp 480-499.

Denzin, N. K., \& Lincoln, Y. S. 1994. Handbook of Qualitative Research. Thousand Oaks, CA: Sage.

De Souza, C. S., \& Preece, J. 2004. “A framework for analyzing and understanding online communities," Interacting with Computers (16:3), pp 579-610.

Earl, J., Hunt, J., \& Garrett, R. K. 2014. Social movements and the ICT revolution. Ch 16 in H. van der Heijden (ed). Handbook of Political Citizenship and Social Movements. Cheltenham, UK: Edward Elgar Publishing, pp 359-383.

Elder, J. 2015. "Ellen Pao is Out as CEO of Reddit,” Wall Street Journal. Retrieved from http://blogs.wsj.com/digits/2015/o7/10/ellen-pao-is-out-as-ceo-of-reddit/

Feinberg, A. 2015. "Reddit in chaos after allegedly firing AMA coordinator Victoria Taylor," Gawker. Retrieved from http://gawker.com/reddit-in-chaos-after-allegedly-firing-ama-coordinator-1715556970

George, A.L., \& Bennett, A. 2005. Case Studies and Theory Development in the Social Sciences. Cambridge, MA: MIT Press.

Goldstone, J.A. 2001. "Toward a fourth generation of revolutionary theory," Annual Review of Political Science (4), pp 139-187.

Greenberg, J., \& Colquitt, J.A. eds., 2005. Handbook of Organizational Justice. Mahwah, NJ: Lawrence Erlbaum.

Hartmann, M. 2015. "What really caused the Reddit revolt?" New York Magazine. Retrieved from http://nymag.com/daily/intelligencer/2015/07/what-really-caused-the-reddit-revolt.html

Hermida, A., Lewis, S. C., \& Zamith, R. 2014. "Sourcing the Arab Spring: A case study of Andy Carvin's sources on Twitter during the Tunisian and Egyptian revolutions," Journal of ComputerMediated Communication (19:3), pp 479-499.

Hoffrage, U., Hertwig, R., \& Gigerenzer, G. 2000. "Hindsight bias: A by-product of knowledge updating?” Journal of Experimental Psychology: Learning, Memory, and Cognition, 26(3), 566-581.

Huffaker, D. 2010. "Dimensions of leadership and social influence in online communities," Human Communication Research (36:4), pp 593-617.

Hutchinson, L. 2015. “Reddit Revolts After Site Lays Off Ask-Me-Anything Employee,” Ars Technica. Retrieved from http://arstechnica.com/business/2015/07/reddit-revolts-after-site-lays-off-askme-anything-employee/

Isaac, M. 2015. "Reddit moderators shut down parts of site over employee’s dismissal,” New York Times. Retrieved from http://www.nytimes.com/2015/07/04/technology/reddit-moderatorsshut-down-parts-of-site-over-executives-dismissal.html

Isaac, M. and Strietfield, D. 2015. "It's Silicon Valley 2, Ellen Pao o: Fighter of sexism is out at Reddit," New York Times. Retrieved from http://www.nytimes.com/2015/o7/11/technology/ellen-paoreddit-chief-executive-resignation.html

Kozinets, R.V. 2015. Netnography: Redefined. Thousand Oaks, CA: Sage Publications. 
Kraut, R. E., Resnick, P. 2012. Building successful online communities: Evidence-based social design. Cambridge, MA: MIT Press.

Langley, A. 1999. "Strategies for theorizing from process data," Academy of Management Review (24:4), pp.691-710.

Lynch, B., \& Swearington, C. 2015. "Why we shut down Reddit's 'Ask Me Anything' forum," The New York Times. Retrieved from http://www.nytimes.com/2015/07/08/opinion/why-we-shutdown-reddits-ask-me-anything-forum.html

McWhertor, M. 2015. "Bethesda responds to blowback over Skyrim paid mods on Steam, says it's listening," Polygon. Retrieved from http://www.polygon.com/2015/4/27/8505513/bethesdaskyrim-paid-mods-valve-steam

Matias, J N. 2015. "What just happened on Reddit? Understanding the moderator blackout," Social Media Collective, Microsoft England. Retrieved from http://socialmediacollective.org/2015/07/09/what-just-happened-on-reddit-understandingthe-moderator-blackout/\#godark

Miles, M. B., Huberman, A. M., \& Saldaña, J. 2013. Qualitative data analysis: A methods sourcebook. Thousand Oaks, CA: Sage.

Miranda, S. M., Young, A., \& Yetgin, E. 2016. "Are social media emancipatory or hegemonic? Societal effects of mass media digitization," MIS Quarterly (40:2), pp 303-329

Mozilla Organization 2015. Mozilla Organizations. Retrieved from https://www.mozilla.org/enUS/about/governance/organizations/

Mozilla Press Center. 2014. FAQ on CEO Resignation. Retrieved from https://blog.mozilla.org/blog/2014/04/05/faq-on-ceo-resignation/

Orland, K. 2015. "Gabe Newell addresses controversy over paid Steam mods," Ars Technica. Retrieved from http://arstechnica.com/gaming/2015/04/steam-workshop-lets-users-sell-mods-but-onlyshares-25-percent-of-revenue/

Plant, R. 2004. "Online communities," Technology in Society, (26:1), pp 51-65.

Pfeffer, J., \& Salancik, G. R. 1978. The external control of organizations: A resource dependence perspective. Palo Alto, CA: Stanford University Press.

Preece, J. 2000. Online communities: Designing usability and supporting sociability. New York, NY:John Wiley \& Sons, Inc.

Preece, J., \& Maloney-Krochmar, D. 2006. "Online communities: Design, theory, and practice," Journal of Computer-Mediated Communication (10:4).

Rao, H., \& Dutta, S. 2012. "Free spaces as organizational weapons of the weak: Religious festivals and regimental mutinies in the 1857 Bengal Native Army," Administrative Science Quarterly (57:4), pp 625-668.

Saldaña, J. 2015. The Coding Manual for Qualitative Researchers. Thousand Oaks, CA: Sage Publications.

Selander, L. \& Jarvenpaa, S. 2016. "Digital action repertoires and transforming a social movement organization," MIS Quarterly (40:2), pp 331-352.

Strauss, A., \& Corbin, J. 1990. Basics of qualitative research (Vol. 15). Thousand Oaks, CA: Sage.

Suler, J. 2004. “The online disinhibition effect," Cyberpsychology \& behavior (7:3), pp 321-326.

Yetgin, E., Young, A. G., \& Miranda, S. M. 2012. "Cultural production of protest frames and tactics: Cybermediaries and the SOPA movement," Proceedings of the International Conference on Information Systems (ICIS 2012). 